\title{
Relapse according to antipsychotic treatment in schizophrenic patients: a propensity- adjusted analysis
}

Aurelie Millier ${ }^{1}$, Emmanuelle Sarlon ${ }^{2,3,4}$, Jean-Michel Azorin ${ }^{5}$, Laurent Boyer ${ }^{6 *}$, Samuel Aballea ${ }^{1}$, Pascal Auquier ${ }^{6}$, Mondher Toumi ${ }^{7^{*}}$

\begin{abstract}
Objective: To compare the rate of relapse as a function of antipsychotic treatment (monotherapy vs. polypharmacy) in schizophrenic patients over a 2-year period.

Methods: Using data from a multicenter cohort study conducted in France, we performed a propensity-adjusted analysis to examine the association between the rate of relapse over a 2-year period and antipsychotic treatment (monotherapy vs. polypharmacy).
\end{abstract}

Results: Our sample consisted in 183 patients; 50 patients (27.3\%) had at least one period of relapse and 133 had no relapse (72.7\%). Thirty-eight (37.7) percent of the patients received polypharmacy. The most severely ill patients were given polypharmacy: the age at onset of illness was lower in the polypharmacy group $(p=0.03)$. Patients that received polypharmacy also presented a higher general psychopathology PANSS subscore $(p=0.04)$ but no statistically significant difference was found in the PANSS total score or the PANSS positive or negative subscales. These patients were more likely to be given prescriptions for sedative drugs $(p<0.01)$ and antidepressant medications ( $p=0.03$ ). Relapse was found in $23.7 \%$ of patients given monotherapy and $33.3 \%$ given polypharmacy $(p=0.16)$. After stratification according to quintiles of the propensity score, which eliminated all significant differences for baseline characteristics, antipsychotic polypharmacy was not statistically associated with an increase of relapse: $\mathrm{HR}=1.686(0.812 ; 2.505)$.

Conclusion: After propensity score adjustment, antipsychotic polypharmacy is not statistically associated to an increase of relapse. Future randomised studies are needed to assess the impact of antipsychotic polypharmacy in schizophrenia.

\section{Background}

Antipsychotic medication is described as the cornerstone of schizophrenia treatment, as it offers benefits for controlling symptoms and preventing relapse. Antipsychotic monotherapy is generally recommended by guidelines as the treatment of choice [1]. However, treatment resistance represents a significant clinical problem [2]. One-fifth to one-third of people with schizophrenia are

\footnotetext{
* Correspondence: laurent.boyer@ap-hm.fr; mondher.toumi@univ-lyon1.fr ${ }^{6}$ Department of Public Health, EA 3279 Research Unit, University Hospital, Boulevard Jean Moulin 13385 Marseille, France

${ }^{7}$ UCBL 1 - Chair of Market Access University Claude Bernard Lyon I, Decision Sciences \& Health Policy, Boulevard du 11 Novembre 1918, 69622 Villeurbanne, France

Full list of author information is available at the end of the article
}

considered to have illness that is resistant to treatment [3]. In this context, antipsychotic combination treatment, also called antipsychotic polypharmacy, has been frequently used in clinical practice. An increasing trend of antipsychotic polypharmacy has been described in Western countries [4], and the prevalence rate is estimated to be between $27 \%$ and $60 \%$ [5-9].

However, it remains unclear if there is an evidence base to support antipsychotic polypharmacy $[3,6]$. According to several observational studies, antipsychotic polypharmacy was associated with higher rates of extrapyramidal side effects than antipsychotic monotherapy. Further, antipsychotic polypharmacy was also reported to decrease adherence to treatment and to increase

\section{Biomed Central}

(c) 2011 Millier et al; licensee BioMed Central Ltd. This is an Open Access article distributed under the terms of the Creative Commons Attribution License (http://creativecommons.org/licenses/by/2.0), which permits unrestricted use, distribution, and reproduction in any medium, provided the original work is properly cited. 
relapse and mortality compared to antipsychotic monotherapy $[3,6,10,11]$. However, in a recent meta-analysis Correll et al. [2] found that antipsychotic polypharmacy might be superior to monotherapy with respect to general measures of efficacy in certain clinical situations. Other studies did not find any statistical link between polypharmacy and mortality risk [12-14].

Consequently, the impact of antipsychotic polypharmacy requires further study to derive clinical recommendations [2]. According to Faries et al. [6], the reasons for the inconsistent findings may stem from methodological issues that need to be considered. Available randomised evidence is limited [2] because of the difficulties in conducting randomised controlled trials on this subject. Primarily, studies of an observational nature have been conducted and have provided useful information. However, using observational data to compare outcomes associated with antipsychotic polypharmacy may result in biased estimates [15]. Because the type of treatment (monotherapy or polypharmacy) was not randomly assigned in these prior studies, patients with specific characteristics, such as disease severity, could have been more likely to have been treated with polypharmacy. As these characteristics might be related to study outcomes, a direct comparison between patients with monotherapy and polypharmacy could have been biased. Moreover, the majority of studies with antipsychotics thus far have been of relatively short duration, and consequently there is a lack of evidence regarding their efficacy in the prevention of relapse in the long term [2].

The objective of the present study was to compare the occurrence of relapse according to antipsychotic treatment at baseline (monotherapy vs. polypharmacy), in a two-year observational cohort of French schizophrenic patients, using a propensity-adjusted analysis. Propensity analysis attempts to compare outcomes between two groups that have a similar distribution of measured covariates and, in this way, approximates the conditions of random site-of-treatment assignment [16].

\section{Methods}

\subsection{Study design and sample}

The data are from the European Schizophrenia Cohort (EuroSC), conducted in the UK, France, and Germany. A detailed description of the European Schizophrenia Cohort has been published earlier [17]. In brief, it is a naturalistic 2-year follow-up of a cohort of people suffering from schizophrenia. The principle objective of the EuroSC was to identify and describe the types of treatment and methods of care for people with schizophrenia and to correlate these with clinical outcomes, states of health, and quality of life [17-24]. In our study, we only included French samples to control for country variation in the management of schizophrenia, which can be a confounding bias. We have shown previously that service use varied considerably between the three participating countries [19]. The French health system may offer an interesting approach: universal access to care, totally free health-care, and access to the most appropriate treatment, regardless of cost. This cohort of people suffering from schizophrenia was from three catchment areas in France: northern France (Lille), central France (Lyon and Clermont-Ferrand), and southern France (Marseille and Toulon). Each of these areas covers an urban centre of approximately one million inhabitants living in a city or in medium-size towns. In each area, patients treated in the "psychiatric sector" [25] were identified according to the following criteria: diagnosis of schizophrenia according to the DSM-IV criteria [26], aged 18 to 64 years, and French as native language. Random sampling from these patients was used to generate a representative sample.

A total of 183 patients were followed for a 2-year period from 1998 to 2000, with data collected every 6 months. If the participant withdrew consent at any time or if the participant was lost to follow-up, data collected up to this point were used in analysis. This project was conducted in accordance with the Declaration of Helsinki and French Good Clinical Practices [27,28]. The protocol of this study was approved by the Institution Review Board or the Ethic Committee responsible for the participating hospital or institution. Written informed consent was obtained from each participant after the study details had been fully explained.

\subsection{Data collection}

The following data were collected.

1. Socio-demographic information: gender, age, and living situation.

2. Clinical characteristics: psychotic symptoms based on the Positive and Negative Syndrome Scale (PANSS), which comprises three different subscales (positive, negative and general psychopathology) [29,30]; Functioning based on the Global Assessment of Functioning (GAF) scale [31], the Global Assessment of Relational Functioning (GARF) [32] and the Social and Occupational Functioning Assessment Scale (SOFAS) [33]; depression based on the Calgary Depression Scale for Schizophrenia (CDSS), specifically designed for schizophrenic patients, which evaluates depression independent of extra-pyramidal and negative symptoms [34,35].

3. Drug information: antipsychotic medication (monotherapy vs. polypharmacy): at baseline, patients were queried about their use of medications. Monotherapy (polypharmacy) was defined as the occurrence of one (more than one) ongoing antipsychotic medication prescription on the day of the visit; sedative drugs, 
antidepressant and side-effects co-treatment; the Simpson and Angus Scale (SAS) [36], the Barnes Akathisia Scale (BAS) [37], and the Abnormal Involuntary Movement Scale (AIMS) [38] were used to assess the side-effects; the Rating of Medication Influences (ROMI) Scale was used to evaluate adherence to treatment [39]. The ROMI is a reliable and valid instrument that can be used to assess the patient's subjective reasons for medication compliance and non-compliance.

4. The number of previous hospitalisations.

5. Quality of life (QoL) questionnaire:

SF-36 is a generic, self-administered QoL questionnaire consisting of 36 items describing 8 dimensions: Physical Functioning (PF); Social Functioning (SF); Role-Physical Problems (RPP); Role-Emotional Problems (REP); Mental Health (MH); Vitality (VIT); Bodily Pain (BP); and General Health (GH). Each dimension is scored within a range from 0 (low QoL level) to 100 (high QoL level) [40,41].

\subsection{Study outcome}

Our primary outcome was relapse on a 2-year period, defined according to a usual, clinically reproducible and validated definition [42,43]: (1) hospitalisation due to worsening of psychotic symptoms or an unequivocal worsening of psychotic symptoms of such magnitude that hospitalisation appeared imminent, or (2) a reemerge of florid psychotic symptoms such as delusions, hallucinations, bizarre behaviour, or (3) thought disorder lasting seven days or more.

This information was collected by routine clinical interview by a psychiatrist every six months, and relapse was defined using information regarding the baseline characteristics of the patient. Additional relevant information was obtained from the medical record and also through staff interviews.

\subsection{Statistical analysis}

Characteristics for patients were compared using the Chi-squared or Fisher exact tests for categorical variables and the Wilcoxon rank sum test for continuous variables. We performed a propensity score analysis to adjust for imbalances in baseline characteristics between patients with monotherapy and polypharmacy. For this purpose, we first developed a nonparsimonious logistic regression model to derive a propensity score for patients receiving polypharmacy based on all the covariates [44]. This logistic regression model yielded a c-statistic of 0.80 , indicating a strong ability to discriminate between monotherapy and polypharmacy. This logistic regression model was used to estimate a propensity score for each patient, corresponding to the probability of being treated using polypharmacy. Patients were stratified by quintile of increasing propensity score. To validate our propensity score adjustment, we checked for adequate overlap in propensity scores for monotherapy and polypharmacy within each quintile and for the absence of significant residual imbalances in patient characteristics after adjustment for quintile of the propensity score. A multivariable Cox proportional hazards model was used to estimate the Hazard Ratio (HR) and its corresponding 95\% confidence interval (CI) of relapse associated with polypharmacy after adjusting for the strata of propensity score.

Statistical analyses were carried out using SAS 9.1. The statistical significance level was set at $\mathrm{p}<0.05$ in a two-sided test.

\section{Results}

Our sample consisted of 183 patients; 50 patients $(27.3 \%)$ had at least one relapse and, 133 patients had no relapse $(72.7 \%)$. Males comprised $70.9 \%$ of patients, and the mean age was 24.8 years (standard deviation = $8.0)$. Of the 183 patients who were included in the study, 45 patients did not complete the two years of follow up (24.6\%). The characteristics at baseline were similar for patients with complete follow up $(n=138)$ and without complete follow up $(\mathrm{n}=45)$ (all p-values $>$ 0.05).

\subsection{Baseline characteristics of patients with monotherapy and polypharmacy}

Characteristics for the monotherapy and polypharmacy groups are shown in Table 1. Sixty-two (62.3\%) of the patients had monotherapy, and $37.7 \%$ of patients received polypharmacy. In the polypharmacy group, 54 patients received two antipsychotics (78.3\%), and 15 patients received three antipsychotics (21.7\%). Twenty-two patients in the polypharmacy group (31.9\%) and 37 patients in the monotherapy group (32.5\%) received a depot antipsychotic medication. There was no significant difference in socio-demographic and clinical characteristics between the two groups, except for the age at onset of illness, which was lower in the polypharmacy group $(\mathrm{p}=0.03)$, and the general psychopathology PANSS score, which was higher in the polypharmacy group $(p=0.04)$. The proportion of patients receiving antidepressant and sedative drugs was significantly higher in the polypharmacy group (respectively $\mathrm{p}=0.03$ and $\mathrm{p}<0.01$ ). Side effects, as assessed with the AIMS, BAS, and SAS, did not differ between the two groups, whereas we identified a higher proportion of patients with drugs to correct side effects in the polypharmacy group $(\mathrm{p}<0.01)$. Concerning QoL scores, we did not find any statistical difference except for the Role-Emotional limitations (problems with work or other daily activities as a result of emotional problems), which was lower in the polypharmacy group $(\mathrm{p}=0.03)$. 
Table 1 Baseline characteristics for schizophrenic patients with monotherapy and polypharmacy $(n=183)$

\begin{tabular}{|c|c|c|c|c|c|}
\hline & \multicolumn{2}{|c|}{$\begin{array}{l}\text { Patients with monotherapy } \\
\qquad(\mathrm{n}=114)\end{array}$} & \multicolumn{2}{|c|}{$\begin{array}{l}\text { Patients with polypharmacy } \\
\qquad(\mathrm{n}=69)\end{array}$} & \multirow[t]{2}{*}{$P$ value } \\
\hline & M & $(\mathrm{SD})^{1}$ & M & (SD) & \\
\hline \multicolumn{6}{|l|}{ Socio-demographic characteristics } \\
\hline Gender (male), $N(\%)^{2}$ & 79 & $(69.3)$ & 50 & $(73.5)$ & 0.54 \\
\hline Age & 37.9 & $(10.5)$ & 40.6 & $(10.3)$ & 0.08 \\
\hline Living conditions (Alone), N (\%) & 35 & $(30.7)$ & 30 & $(43.5)$ & 0.08 \\
\hline \multicolumn{6}{|l|}{ Clinical characteristics } \\
\hline Age at onset of illness & 25.43 & $(8.20)$ & 22.65 & $(7.28)$ & 0.03 \\
\hline Total PANSS ${ }^{3}$ score & 65.3 & $(18.0)$ & 70.0 & $(22.2)$ & 0.14 \\
\hline Positive PANSS score & 14.0 & $(5.3)$ & 13.7 & $(5.6)$ & 0.74 \\
\hline Negative PANSS score & 18.0 & $(6.9)$ & 19.6 & $(8.2)$ & 0.16 \\
\hline General Psychopathology PANSS score & 33.3 & $(9.8)$ & 36.7 & $(11.6)$ & 0.04 \\
\hline $\mathrm{GAF}^{4}$ score & 54.0 & $(14.0)$ & 51.0 & $(16.3)$ & 0.20 \\
\hline GARF $^{5}$ score & 55.7 & $(16.7)$ & 54.3 & $(17.7)$ & 0.59 \\
\hline SOFAS ${ }^{6}$ score & 53.9 & $(13.4)$ & 50.7 & $(15.7)$ & 0.15 \\
\hline CDSS $^{7}$ score & 2.7 & $(3.3)$ & 3.8 & $(4.1)$ & 0.07 \\
\hline \multicolumn{6}{|l|}{ Medication } \\
\hline Drugs for side-effects ${ }^{\S}, \mathrm{N}(\%)$ & 40 & $(35.0)$ & 42 & $(60.9)$ & $<0.01$ \\
\hline Sedative drugs ${ }^{\S \S}, N(\%)$ & 49 & $(43.0)$ & 46 & $(66.7)$ & $<0.01$ \\
\hline Antidepressant, N (\%) & 18 & $(15.8)$ & 20 & $(29.0)$ & 0.03 \\
\hline AIMS $^{8}$ & 2.7 & $(4.3)$ & 3.1 & $(4.6)$ & 0.53 \\
\hline $\mathrm{BAS}^{9}$ & 1.0 & $(1.9)$ & 1.1 & $(2.1)$ & 0.71 \\
\hline SAS $^{10}$ & 2.9 & $(3.3)$ & 3.8 & $(4.0)$ & 0.13 \\
\hline \multicolumn{6}{|l|}{$\mathrm{ROMI}^{11}$} \\
\hline Compliance score & 12.2 & $(2.8)$ & 13.0 & $(2.7)$ & 0.09 \\
\hline Non compliance score & 14.2 & $(3.7)$ & 14.0 & $(3.8)$ & 0.74 \\
\hline Number of previous hospitalisations & 5.5 & $(5.3)$ & 7.5 & $(6.9)$ & 0.05 \\
\hline \multicolumn{6}{|l|}{ Quality of life: SF-36 } \\
\hline Physical Functioning & 82.0 & $(20.5)$ & 76.3 & $(22.9)$ & 0.10 \\
\hline Role-Physical Limitations & 74.2 & $(32.9)$ & 65.9 & $(40.2)$ & 0.15 \\
\hline Bodily Pain & 72.7 & $(26.3)$ & 71.9 & $(27.6)$ & 0.85 \\
\hline General Health & 58.2 & $(21.4)$ & 58.3 & $(21.0)$ & 0.98 \\
\hline Vitality & 50.9 & $(19.1)$ & 48.0 & $(17.9)$ & 0.34 \\
\hline Mental Health & 63.4 & $(20.4)$ & 59.5 & $(17.3)$ & 0.21 \\
\hline Role-Emotional Limitations & 74.3 & $(36.4)$ & 60.8 & $(40.2)$ & 0.03 \\
\hline Social Functioning & 68.9 & $(30.1)$ & 67.1 & $(25.8)$ & 0.70 \\
\hline Relapse, N (\%) & 27 & $(23.7)$ & 23 & $(33.3)$ & 0.16 \\
\hline \multicolumn{6}{|c|}{$\begin{array}{l}{ }^{3} \text { Positive and Negative Syndrome Scale; }{ }^{4} \text { Global Assessment Functioning; }{ }^{5} \text { Global Assessment of Relational Functioning; }{ }^{6} \text { Social and Occupational Functioning } \\
\text { Assessment Scale; }{ }^{7} \text { Calgary Depression Scale for Schizophrenia; }{ }^{8} \text { Abnormal Involuntary Movement Score; }{ }^{B} \text { Barnes Akathisia score; }{ }^{10} \text { Simpson-Angus score; }{ }^{11} \text { Rating } \\
\text { of Medication Influences Scale. }\end{array}$} \\
\hline \multicolumn{6}{|c|}{ §Drugs for side effects: Biperiden hydrochloride, Tropatepine hydrochloride, and Trihexyphenidyl hydrochloride. } \\
\hline & & & & & \\
\hline
\end{tabular}

\subsection{Factors associated with relapse}

Characteristics for the patients with relapse and no relapse are shown in Table 2. Patients with relapse were significantly younger than patients with no relapse $(\mathrm{p}=0.04)$. In the same way, the age at onset of illness was lower for patients with relapse than for those without relapse $(\mathrm{p}<0.01)$. Patients with relapse were also less likely to report living independently $(\mathrm{p}=0.04)$. Except for these three characteristics, no significant differences were found in the univariate analysis. The proportion of polypharmacy subjects between the relapse $(46.0 \%)$ and non-relapse $(34.6 \%)$ groups did not differ significantly $(\mathrm{p}=0.15)$. 
Table 2 Univariate and propensity score-stratified models: Hazard Ratio (HR) and its corresponding $95 \%$ confidence interval $(\mathrm{Cl})$ for risk factors associated with relapse $(n=183)$

\begin{tabular}{|c|c|c|c|c|c|c|c|}
\hline & \multicolumn{2}{|c|}{$\begin{array}{l}\text { Patients with relapse } \\
(\mathrm{n}=50)\end{array}$} & \multicolumn{2}{|c|}{$\begin{array}{l}\text { Patients with no relapse } \\
\qquad(n=133)\end{array}$} & \multicolumn{3}{|c|}{ Propensity score-stratified model } \\
\hline & $M$ & $(S D)^{1}$ & $M$ & (SD) & $P$ value & HR & $(95 \% \mathrm{Cl})$ \\
\hline \multicolumn{8}{|l|}{ Socio-demographic characteristics } \\
\hline Gender (male), N (\%) ${ }^{2}$ & 34 & $(68.0)$ & 95 & $(72.0)$ & 0.60 & - & - \\
\hline Age & 36.3 & $(9.7)$ & 39.9 & $(10.6)$ & 0.04 & - & - \\
\hline Living conditions (Alone), N (\%) & 12 & $(24.0)$ & 53 & (39.9) & 0.04 & - & - \\
\hline \multicolumn{8}{|l|}{ Clinical characteristics } \\
\hline Age at onset of illness & 21.5 & $(5.6)$ & 25.4 & $(8.4)$ & $<0.01$ & - & - \\
\hline Total PANSS ${ }^{3}$ score & 66.4 & $(18.7)$ & 67.4 & $(20.2)$ & 0.76 & - & - \\
\hline Positive PANSS score & 14.6 & $(5.4)$ & 13.6 & $(5.5)$ & 0.26 & - & - \\
\hline Negative PANSS score & 17.7 & $(6.5)$ & 19.0 & $(7.8)$ & 0.31 & - & - \\
\hline General Psychopathology PANSS score & 34.0 & $(10.9)$ & 34.8 & $(10.5)$ & 0.66 & - & - \\
\hline $\mathrm{GAF}^{4}$ score & 51.9 & $(14.2)$ & 53.3 & $(15.2)$ & 0.58 & - & - \\
\hline GARF $^{5}$ score & 54.2 & $(15.9)$ & 55.5 & $(17.5)$ & 0.64 & - & - \\
\hline SOFAS ${ }^{6}$ score & 52.0 & $(14.4)$ & 52.9 & $(14.4)$ & 0.72 & - & - \\
\hline $\mathrm{CDSS}^{7}$ score & 3.9 & $(4.5)$ & 2.8 & (3.3) & 0.11 & - & - \\
\hline
\end{tabular}

\section{Medication}

Drugs for side-effects, N (\%)

Sedatives drugs, N (\%)

Antidepressants, N (\%)

AIMS $^{8}$

BAS $^{9}$

SAS $^{10}$

ROMI ${ }^{11}$

\begin{tabular}{|c|c|c|c|c|c|c|c|}
\hline Compliance score & 12.9 & $(2.6)$ & 12.4 & $(2.8)$ & 0.20 & & \\
\hline Non compliance score & 14.5 & $(3.8)$ & 14.0 & $(3.7)$ & 0.40 & & \\
\hline Number of previous hospitalisations & 7.7 & $(7.2)$ & 5.7 & $(5.5)$ & 0.10 & & \\
\hline \multicolumn{8}{|l|}{ Quality of life:SF-36 } \\
\hline Physical Functioning & 83.3 & $(18.8)$ & 78.8 & $(22.3)$ & 0.23 & - & - \\
\hline Role-Physical Limitations & 66.5 & $(39.1)$ & 72.7 & (34.6) & 0.32 & - & - \\
\hline Bodily Pain & 69.4 & $(27.6)$ & 73.4 & $(26.4)$ & 0.39 & - & - \\
\hline General Health & 55.8 & $(22.5)$ & 59.1 & $(20.8)$ & 0.38 & - & - \\
\hline Vitality & 51.5 & (16.6) & 49.3 & $(29.4)$ & 0.50 & - & - \\
\hline Mental Health & 61.9 & (19.5) & 62.1 & (19.4) & 0.96 & - & - \\
\hline Role-Emotional Limitations & 63.2 & (39.1) & 71.5 & $(38.0)$ & 0.22 & - & - \\
\hline Social Functioning & 68.6 & $(27.7)$ & 68.2 & (29.0) & 0.93 & - & - \\
\hline Polypharmacy & 23 & $(46.0)$ & 46 & $(34.6)$ & 0.15 & 1.686 & $(0.812 ; 2.505)$ \\
\hline
\end{tabular}

${ }^{1}$ Mean (Standard Deviation).

${ }^{2}$ Effective (Percentage).

${ }^{3}$ Positive and Negative Syndrome Scale; ${ }^{4} \mathrm{Global}$ Assessment Functioning; ${ }^{5} \mathrm{Global}$ Assessment of Relational Functioning; ${ }^{6}$ Social and Occupational Functioning Assessment Scale; ${ }^{7}$ Calgary Depression Scale for Schizophrenia; ${ }^{8}$ Abnormal Involuntary Movement Score; ${ }^{9}$ Barnes Akathisia score; ${ }^{10}$ Simpson-Angus score; ${ }^{11}$ Rating of Medication Influences Scale.

Values significant at the $5 \%$ level are marked in bold.

In the propensity-adjusted analysis, antipsychotic polypharmacy was not statistically associated with an increase of relapse: $\mathrm{HR}=1.686(0.812 ; 2.505)$.

\section{Discussion}

We found that antipsychotic polypharmacy in schizophrenic patients was not statistically associated with an increase in relapse in this observational study relying on a propensity score adjustment. Although a recent meta-analysis showed that antipsychotic polypharmacy may be superior to monotherapy [2], the majority of previous studies reported higher rates of side effects and relapse $[3,6,10,11,45]$. 
Several hypotheses can be proposed to explain our result.

One hypothesis is that previous studies have varied in design, potential predictors, sample examined, and the manner in which relapse was defined and measured [6]. Our study presents characteristics that can explain why our results are not entirely consistent with those of other studies. Our findings are based on naturalistic observational data. The results of observational studies reflect the patterns of practice and can be considered as more meaningful than clinical trials to evaluate effectiveness, notably on long-term outcomes such as relapse. We also conducted a 2-year follow up of schizophrenic patients, which is longer than those used in the majority of clinical trials and observational studies [3]. Clinical trials with antipsychotics thus far have been of relatively short duration [2]. Finally, we used a propensity score adjustment rarely performed on the previous observational studies. A propensity score is a better option than multivariate logistic regression when events are few and various confounding factors coexist [46].

Our findings suggest that the most severely ill patients were given polypharmacy, which can potentially bias findings of previous studies. In our study, the age at illness onset was lower in the polypharmacy group than in the monotherapy group. The age of illness onset is widely accepted as having particularly powerful clinical and prognostic significance. A recent meta-analysis supports the view that severity of disease process is associated with early onset [47]. Patients receiving polypharmacy also presented a higher general psychopathology PANSS score than patients with monotherapy. However, this statistically significant difference may not be clinically relevant, and no statistically significant difference was found in the PANSS total score or the PANSS positive or negative subscales. They were also more likely to be given prescriptions for sedative drugs than patients receiving monotherapy. These findings are consistent with a study showing that patients who received antipsychotic combinations exhibited more positive and excited symptoms than patients given prescriptions for monotherapy [48]. Additionally, the findings support clinicians' reports of using polypharmacy for refractory psychotic symptoms [49-51]. To a lesser extent, patients with polypharmacy were more likely to receive antidepressant medications. This result is concordant with a recent study showing that receiving antidepressants was significantly associated with receiving polypharmacy [52]. This association suggests that patients receiving polypharmacy present displayed more depressive symptoms than did patients receiving monotherapy, and studies have shown that schizophrenic patients with depressive symptoms have poorer longterm functional outcomes [53]. Consequently, the purported association between polypharmacy and poor outcome does not necessarily mean that polypharmacy leads to poor outcome; it may be that poor outcome may lead to aggressive prescription practices that includes high doses and polypharmacy [54]. This major confound, which is not systematically assessed, needs to be addressed in future studies.

Consistent with the results of previous reports [49,55], in our study, patients receiving polypharmacy were more likely to also receive drugs for side-effects than patients with monotherapy. Interestingly, we note in our study that the side effects were assessed with three different standardised instruments, and the adherence of the patients did not differ between the two groups. This can also explain our result by controlling the relation between polypharmacy, side effects as predictor of poor medication adherence, and relapse. Indeed, experts have endorsed side effects or a general fear of side effects as one important factor leading to adherence problems in schizophrenia [56]. In the same way, experts have rated persistent positive or negative symptoms in schizophrenia as the most important symptomatic contributors to adherence problems [56]. The combination of polypharmacy and sedative drugs can explain the absence of differences in persistent positive or negative symptoms between monotherapy and polypharmacy groups. Consequently, this may explain that antipsychotic polypharmacy was not associated to an increase of relapse.

\section{Perspectives and limitations}

Our study had several limitations.

First, the treatment (monotherapy or polypharmacy) was not based on random assignment; therefore, the results may be confounded by other factors. Although the propensity score can adjust for confounding by indication and selection bias, we cannot eliminate residual confounding due to unobserved factors [57]. This limitation of the current work can be moderated by the broad spectrum of characteristics collected in our study. However, well-designed randomised controlled trials are needed to determine the impact of polypharmacy on relapse in schizophrenia.

Second, several interesting data were not analysed. Information regarding dosages of different antipsychotic was not available. Moreover, antipsychotic combinations can be considered as a heterogeneous group, and the different combinations might be associated with different risks of relapse. However, our sample was not sufficient to determine the effect of specific polytherapy combinations.

Third, our sample may not be representative of schizophrenic patients in all of France and in other countries. However, the proportion of polypharmacy and relapse that are in line with previous studies $[3,5,6,8,9,14]$ may indicate a good representativeness. 
Fourth, it is possible that our study lacked statistical power to detect a difference in the rate of relapse. However, our analytical sample comprised 183 patients, 50 of whom had a relapse. This sample size was larger than that of several published randomised controlled trials designed to test the efficacy of polypharmacy vs. monotherapy, especially when we consider the length of the follow up, which were usually shorter in these prior studies than in our study [2].

Finally, a major methodological problem remains in the definition of relapse for schizophrenic patients and the definition of monotherapy and polypharmacy. There are no generally accepted criteria for relapse [42]. However, we have chosen the most consensual definition in the recent scientific literature $[42,43,58]$. Methodological issues to be addressed in future trials should include clinically relevant relapse criteria. In the same way, the definitions of monotherapy and polypharmacy are not consensual. We defined the exposure treatment groups at baseline in a standard way: receiving one antipsychotic at baseline, regardless of medication class or molecule, compared with receiving two or more antipsychotics. We assumed that exposure was relatively stable over time and that the occurrence of relapse may be related to the exposure treatment at baseline. The clinical significance of this study should be cautiously interpreted in accordance with this chosen definition.

\section{Conclusion}

In conclusion, antipsychotic polypharmacy is not statistically associated with an increase in relapse after the propensity adjustment is made. Well-designed randomised controlled trials are needed to assess the impact of antipsychotic polypharmacy in schizophrenia.

\section{Role of Funding Source}

The study was funded by $\mathrm{H}$. Lundbeck A/S.

\section{Declaration of interest}

The authors declare that they have no competing interests.

\begin{abstract}
Acknowledgements
Our thanks to all of the patients and staff who helped with the study: I. Lindenbach, M. Swiridoff, F. Baehr, G. Lauer, T. Schwarz, V. Becker, J. Hoffler K. Siegrist, U. Trenckmann, T.Brugha, J. Smith, D. Bagchi, S. McCormack, S. Wheatley, M. Angermeyer, S. Bernert, R. Kilian, H. Matschinger, C. Mory, C. Roick, M. Goudemand, D. Beaune, S. Dumont, P.Bebbington, D. Ellis, L. Isham, S. Johnson, J. Pearson, E. Perez, A. Regan, R. White, B. Lachaux, P. Pasi-Delay, S. Declerck, J.M. Azorin, J.P.Chabannes, P. Chiaroni, I. Banovic, K. Hansen, C. Morin, L. Munier, J.C. Nachef, C. Nickel, C. Sapin and V. Willacy.
\end{abstract}

\section{Author details}

${ }^{1}$ Creativ-Ceutical France, rue du Faubourg Saint-Honoré, 75008 Paris, France. ${ }^{2}$ National Institute of Health and Medical Research, INSERM, U669, Maison de Solenn, Boulevard de Port Royal, 75679 Paris, France. ${ }^{3}$ University of Paris-Sud and University of Paris Descartes, UMR-S0669, 75014 Paris, France. ${ }^{4}$ Department of Public Health, Hospital Center, Creil/Senlis, 60309 Senlis, France. ${ }^{5}$ Department of Psychiatry, University Hospital Ste-Marguerite,
Boulevard Sainte-Marguerite, 13009 Marseille, France. ${ }^{6}$ Department of Public Health, EA 3279 Research Unit, University Hospital, Boulevard Jean Moulin 13385 Marseille, France. ${ }^{7}$ UCBL 1 - Chair of Market Access University Claude Bernard Lyon I, Decision Sciences \& Health Policy, Boulevard du 11 Novembre 1918, 69622 Villeurbanne, France.

\section{Authors' contributions}

AM, ES and LB wrote the manuscript.

All authors designed the study and wrote the protocol.

AM, ES and LB conducted the literature searches and analyses.

AM conducted the statistical analyses.

All authors contributed to and approved the final manuscript.

Received: 8 November 2010 Accepted: 11 February 2011

Published: 11 February 2011

\section{References}

1. Tandon R, Belmaker RH, Gattaz WF, Lopez-lbor JJ Jr, Okasha A, Singh B, Stein DJ, Olie JP, Fleischhacker WW, Moeller HJ: World Psychiatric Association Pharmacopsychiatry Section statement on comparative effectiveness of antipsychotics in the treatment of schizophrenia. Schizophrenia research 2008, 100(1-3):20-38.

2. Correll CU, Rummel-Kluge C, Corves C, Kane JM, Leucht S: Antipsychotic combinations vs monotherapy in schizophrenia: a meta-analysis of randomized controlled trials. Schizophr Bull 2009, 35(2):443-457.

3. Barbui C, Signoretti A, Mule S, Boso M, Cipriani A: Does the addition of a second antipsychotic drug improve clozapine treatment? Schizophr Bull 2009, 35(2):458-468.

4. Edlinger M, Hausmann A, Kemmler G, Kurz M, Kurzthaler I, Walch T, Walpoth M, Fleischhacker WW: Trends in the pharmacological treatment of patients with schizophrenia over a 12 year observation period. Schizophrenia research 2005, 77(1):25-34.

5. Ballerini A, Boccalon RM, Boncompagni G, Casacchia M, Margari F, Minervini L, Righi R, Russo F, Salteri A, Frediani S, et al: Clinical features and therapeutic management of patients admitted to Italian acute hospital psychiatric units: the PERSEO (psychiatric emergency study and epidemiology) survey. Ann Gen Psychiatry 2007, 6:29.

6. Faries D, Ascher-Svanum H, Zhu B, Correll C, Kane J: Antipsychotic monotherapy and polypharmacy in the naturalistic treatment of schizophrenia with atypical antipsychotics. BMC Psychiatry 2005, 5:26.

7. Jaffe $A B$, Levine J: Antipsychotic medication coprescribing in a large state hospital system. Pharmacoepidemiology and drug safety 2003, 12(1):41-48.

8. Johnsen E, Svingen GF, Jorgensen HA: Practice regarding antipsychotic therapy: a cross-sectional survey in two Norwegian hospitals. Nord J Psychiatry 2004, 58(4):313-317.

9. Kroken RA, Johnsen E, Ruud T, Wentzel-Larsen T, Jorgensen HA: Treatment of schizophrenia with antipsychotics in Norwegian emergency wards, a cross-sectional national study. BMC Psychiatry 2009, 9:24.

10. Gilmer TP, Dolder CR, Lacro JP, Folsom DP, Lindamer L, Garcia P, Jeste DV: Adherence to treatment with antipsychotic medication and health care costs among Medicaid beneficiaries with schizophrenia. Am J Psychiatry 2004, 161(4):692-699.

11. Joukamaa M, Heliovaara M, Knekt P, Aromaa A, Raitasalo R, Lehtinen V: Schizophrenia, neuroleptic medication and mortality. Br J Psychiatry 2006, 188:122-127.

12. Baandrup L, Gasse C, Jensen VD, Glenthoj BY, Nordentoft M, Lublin H, FinkJensen A, Lindhardt A, Mortensen PB: Antipsychotic polypharmacy and risk of death from natural causes in patients with schizophrenia: a population-based nested case-control study. The Journal of clinical psychiatry 2010, 71(2):103-108.

13. Morgan MG, Scully PJ, Youssef HA, Kinsella A, Owens JM, Waddington JL: Prospective analysis of premature mortality in schizophrenia in relation to health service engagement: a 7.5-year study within an epidemiologically complete, homogeneous population in rural Ireland. Psychiatry Res 2003, 117(2):127-135.

14. Tiihonen J, Lonnqvist J, Wahlbeck K, Klaukka T, Niskanen L, Tanskanen A, Haukka J: 11-year follow-up of mortality in patients with schizophrenia: a population-based cohort study (FIN11 study). Lancet 2009, 374(9690):620-627

15. de Leon J: Beyond the "hype" on the association between metabolic syndrome and atypical antipsychotics: the confounding effects of 
cohort, typical antipsychotics, severe mental illness, comedications, and comorbid substance use. J Clin Psychopharmacol 2008, 28(2):125-131 .

16. D'Agostino RB Jr: Propensity score methods for bias reduction in the comparison of a treatment to a non-randomized control group. Stat Med 1998, 17(19):2265-2281.

17. Bebbington PE, Angermeyer M, Azorin JM, Brugha T, Kilian R, Johnson S, Toumi M, Kornfeld A: The European Schizophrenia Cohort (EuroSC): a naturalistic prognostic and economic study. Social psychiatry and psychiatric epidemiology 2005, 40(9):707-717.

18. Heider D, Angermeyer MC, Winkler I, Schomerus G, Bebbington PE, Brugha T, Azorin JM, Toumi M: A prospective study of Quality of life in schizophrenia in three European countries. Schizophrenia research 2007, 93(1-3):194-202.

19. Heider $\mathrm{D}$, Bernert $\mathrm{S}$, Konig $\mathrm{HH}$, Matschinger $\mathrm{H}$, Hogh $\mathrm{T}$, Brugha TS, Bebbington PE, Azorin M, Angermeyer MC, Toumi M: Direct medical mental health care costs of schizophrenia in France, Germany and the United Kingdom - findings from the European Schizophrenia Cohort (EuroSC). Eur Psychiatry 2009, 24(4):216-224.

20. Marwaha S, Johnson S, Bebbington P, Angermeyer MC, Brugha T, Azorin JM, Kilian R, Kornfeld A, Toumi M: Correlates of subjective quality of life in people with schizophrenia: findings from the EuroSC study. The Journal of nervous and mental disease 2008, 196(2):87-94.

21. Marwaha S, Johnson S, Bebbington PE, Angermeyer MC, Brugha TS, Azorin JM, Killian R, Hansen K, Toumi M: Predictors of employment status change over 2 years in people with schizophrenia living in Europe. Epidemiologia e psichiatria sociale 2009, 18(4):344-351.

22. Roick C, Heider D, Bebbington PE, Angermeyer MC, Azorin JM, Brugha TS, Kilian R, Johnson S, Toumi M, Kornfeld A: Burden on caregivers of people with schizophrenia: comparison between Germany and Britain. $\mathrm{Br} J$ Psychiatry 2007, 190:333-338.

23. Schomerus G, Heider D, Angermeyer MC, Bebbington PE, Azorin JM, Brugha T, Toumi M: Residential area and social contacts in schizophrenia. Results from the European Schizophrenia Cohort (EuroSC). Social psychiatry and psychiatric epidemiology 2007, 42(8):617-622.

24. Schomerus $G$, Heider $D$, Angermeyer MC, Bebbington PE, Azorin JM Brugha T, Toumi M: Urban residence, victimhood and the appraisal of personal safety in people with schizophrenia: results from the European Schizophrenia Cohort (EuroSC). Psychological medicine 2008, 38(4):591-597.

25. Verdoux H: The current state of adult mental health care in France. Eur Arch Psychiatry Clin Neurosci 2007, 257(2):64-70.

26. APA: DSM-IV. Diagnostic and Statistical Manual of Mental Disorders. American Psychiatric Association, Washington, DC, 41994

27. CNIL: Act $n^{\circ} 78-17$ of 6 January 1978 on Data Processing, Data Files and Individual Liberties (amended by the Act of 6 August 2004 relating to the protection of individuals with regard to the processing of personal data). Journal officiel de la République Française Assemblée Nationale et Sénat. France; 2004.

28. WMA: Declaration of Helsinki, Ethical Principles for Medical Research Involving Human Subjects. World Medical Association, General Assembly, Seoul, October 2008; 2008

29. Kay SR, Opler LA, Fiszbein A: Significance of positive and negative syndromes in chronic schizophrenia. Br J Psychiatry 1986, 149:439-448.

30. Lancon C, Reine G, Llorca PM, Auquier P: Validity and reliability of the French-language version of the Positive and Negative Syndrome Scale (PANSS). Acta Psychiatr Scand 1999, 100(3):237-243.

31. Endicott J, Spitzer RL, Fleiss JL, Cohen J: The global assessment scale. A procedure for measuring overall severity of psychiatric disturbance. Arch Gen Psychiatry 1976, 33(6):766-771.

32. Dausch BM, Miklowitz DJ, Richards JA: Global assessment of relational functioning scale (GARF): II. Reliability and validity in a sample of families of bipolar patients. Fam Process 1996, 35(2):175-189.

33. Goldman HH, Skodol AE, Lave TR: Revising axis V for DSM-IV: a review of measures of social functioning. Am J Psychiatry 1992, 149(9):1148-1156.

34. Addington D, Addington J, Maticka-Tyndale E: Assessing depression in schizophrenia: the Calgary Depression Scale. Br J Psychiatry Suppl 1993, 22: $39-44$.
35. Lancon C, Auquier P, Reine G, Toumi M, Addington D: Evaluation of depression in schizophrenia: psychometric properties of a French version of the Calgary Depression Scale. Psychiatry Res 1999, 89(2):123-132.

36. Simpson S, Angus R: A rating scale for extrapyramidal side effects. Acta Psychiatr Scand Suppl 1970, , 212: 11-19.

37. Barnes TR: A rating scale for drug-induced akathisia. Br J Psychiatry 1989, 154:672-676

38. Lane RD, Glazer WM, Hansen TE, Berman WH, Kramer SI: Assessment of tardive dyskinesia using the Abnormal Involuntary Movement Scale. The Journal of nervous and mental disease 1985, 173(6):353-357.

39. Weiden P, Rapkin B, Mott T, Zygmunt A, Goldman D, Horvitz-Lennon M, Frances $A$ : Rating of medication influences (ROMI) scale in schizophrenia. Schizophr Bull 1994, 20(2):297-310.

40. Leplege A, Ecosse E, Verdier A, Perneger TV: The French SF-36 Health Survey: translation, cultural adaptation and preliminary psychometric evaluation. J Clin Epidemiol 1998, 51(11):1013-1023.

41. Ware JE Jr, Sherbourne CD: The MOS 36-item short-form health survey (SF-36). I. Conceptual framework and item selection. Med Care 1992, 30(6):473-483.

42. Lader M: What is relapse in schizophrenia? Int Clin Psychopharmacol 1995, 9(Suppl 5):5-9.

43. Leucht S, Heres S, Hamann J, Kane JM: Methodological issues in current antipsychotic drug trials. Schizophr Bull 2008, 34(2):275-285.

44. Austin PC, Grootendorst P, Normand SL, Anderson GM: Conditioning on the propensity score can result in biased estimation of common measures of treatment effect: a Monte Carlo study. Stat Med 2007, 26(4):754-768

45. Correll CU, Frederickson AM, Kane JM, Manu P: Does antipsychotic polypharmacy increase the risk for metabolic syndrome? Schizophrenia research 2007, 89(1-3):91-100.

46. Cepeda MS, Boston R, Farrar JT, Strom BL: Comparison of logistic regression versus propensity score when the number of events is low and there are multiple confounders. Am J Epidemiol 2003, 158(3):280-287.

47. Raji TK, Ismail Z, Mulsant BH: Age at onset and cognition in schizophrenia: meta-analysis. Br J Psychiatry 2009, 195(4):286-293.

48. Centorrino F, Fogarty KV, Sani G, Salvatore P, Cincotta SL, Hennen J, Guzzetta F, Talamo A, Saadeh MG, Baldessarini RJ: Use of combinations of antipsychotics: McLean Hospital inpatients, 2002. Hum Psychopharmacol 2005, 20(7):485-492.

49. Kreyenbuhl JA, Valenstein M, McCarthy JF, Ganoczy D, Blow FC: Long-term antipsychotic polypharmacy in the VA health system: patient characteristics and treatment patterns. Psychiatr Serv 2007, 58(4):489-495

50. Sernyak MJ, Rosenheck R: Clinicians' reasons for antipsychotic coprescribing. The Journal of clinical psychiatry 2004, 65(12):1597-1600

51. Tapp A, Wood AE, Secrest L, Erdmann J, Cubberley L, Kilzieh N: Combination antipsychotic therapy in clinical practice. Psychiatr Serv 2003, 54(1):55-59.

52. Mojtabai R, Olfson M: National trends in psychotropic medication polypharmacy in office-based psychiatry. Arch Gen Psychiatry 67(1):26-36.

53. Conley RR, Ascher-Svanum H, Zhu B, Faries DE, Kinon BJ: The burden of depressive symptoms in the long-term treatment of patients with schizophrenia. Schizophrenia research 2007, 90(1-3):186-197.

54. Citrome L, Jaffe A, Levine J: Monotherapy versus polypharmacy for hospitalized psychiatric patients. Am J Psychiatry 2005, 162(3):631, author reply 632-633.

55. Procyshyn RM, Kennedy NB, Tse G, Thompson B: Antipsychotic polypharmacy: a survey of discharge prescriptions from a tertiary care psychiatric institution. Can J Psychiatry 2001, 46(4):334-339.

56. Velligan DI, Weiden PJ, Sajatovic M, Scott J, Carpenter D, Ross R, Docherty JP: The expert consensus guideline series: adherence problems in patients with serious and persistent mental illness. The Journal of clinical psychiatry 2009, 70(Suppl 4):1-46, quiz 47-48.

57. Rubin DB: Estimating causal effects from large data sets using propensity scores. Ann Intern Med 1997, 127(8 Pt 2):757-763. 
58. Leucht S, Barnes TR, Kissling W, Engel RR, Correll C, Kane JM: Relapse prevention in schizophrenia with new-generation antipsychotics: a systematic review and exploratory meta-analysis of randomized, controlled trials. Am J Psychiatry 2003, 160(7):1209-1222.

\section{Pre-publication history}

The pre-publication history for this paper can be accessed here: http://www.biomedcentral.com/1471-244X/11/24/prepub

doi:10.1186/1471-244X-11-24

Cite this article as: Millier et al:: Relapse according to antipsychotic treatment in schizophrenic patients: a propensity-adjusted analysis. BMC Psychiatry 2011 11:24.

Submit your next manuscript to BioMed Central and take full advantage of:

- Convenient online submission

- Thorough peer review

- No space constraints or color figure charges

- Immediate publication on acceptance

- Inclusion in PubMed, CAS, Scopus and Google Scholar

- Research which is freely available for redistribution

Submit your manuscript at www.biomedcentral.com/submit 